\title{
Evaluating and Strengthening the Health System of Curaçao to Improve its Performance for Future Outbreaks of Infectious Diseases.
}

Vaitiare Mulderij-Jansen ( $\nabla$ v.i.c.jansen@outlook.com )

Universitair Medisch Centrum Groningen https://orcid.org/0000-0002-6793-8007

Izzy Gerstenbluth

Curacao Biomedical \& Health Research Institute

\section{Ashley Duits}

Curacao Biomedial \& Health Research Institute

\section{Adriana Tami}

Universitair Medisch Centrum Groningen Afdeling Medische Microbiologie en Infectiepreventie

Ajay Bailey

Utrecht University Faculty of Geosciences: Universiteit Utrecht Faculteit Geowetenschappen

\section{Research}

Keywords: Caribbean, Dengue, Zika, Chikungunya, Vector control, Surveillance system, Communication, Strengthing, WHO health system building blocks, Small Island Developing States

Posted Date: March 23rd, 2021

DOl: https://doi.org/10.21203/rs.3.rs-340314/v1

License: (9) (1) This work is licensed under a Creative Commons Attribution 4.0 International License. Read Full License 


\section{Abstract}

\section{Background}

Vector-borne diseases (VBDs) such as dengue, chikungunya, and Zika pose a significant challenge to health systems in countries they affect, especially countries with less developed healthcare systems. Therefore countries are encouraged to strengthen their healthcare systems to achieve more resilient systems. This qualitative study aims to examine the performance of the health system of the Dutch Caribbean island of Curaçao with regards to the prevention and control of VBDs in the last decennium by using the WHO health system building blocks.

\section{Methods}

From January 2019 to February 2020, a multi-method qualitative study was performed in Curaçao., applying content analysis of documents $(n=50)$, five focus group discussions $(n=30)$, interviews with experts $(n=11)$, and fifteen observation sessions. The study was designed based on the WHO framework: health system building blocks. Two cycles of inductive and deductive coding were employed, and Nvivo software was used to analyse the data.

\section{Results}

This study's data highlighted the challenges (e.g., insufficient oversight, coordination, leadership skills, structure, and communication) that the departments of the health system of Curaçao faced during the last three epidemics of VBDs (2010-2020). Furthermore, low levels of collaboration between governmental and non-governmental organisations (e.g., semi-governmental and private laboratories) and insufficient capacity building to improve skills (e.g., entomological, surveillance skills) were also observed. Lastly, we observed how bottlenecks in one building block negatively influenced other building blocks (e.g., inadequate leadership/governance obstructed the workforce's performance).

\section{Conclusions}

This study uncovers potential organisational bottlenecks that have affected the performance of the health system of Curaçao negatively. We recommend starting with the reinforcement of oversight of the integrated vector management program to ensure the development, implementation, and evaluation of related legislation, policies, and interventions. Also, we recommend evaluating and reform the existing administrative and organisational structure of the health system by taking the cultural style, challenges, and barriers of the current health system into account. More efforts are needed to improve the documentation of agreements, the recruitment, and evaluation of the workforce's performance. Based on our findings, we conceptualised actions to strengthen the health system's building blocks to improve its performance for future outbreaks of infectious diseases.

\section{Background}


Dengue (DENV), chikungunya (CHIKV), and Zika (ZIKV) viruses are responsible for significant epidemics worldwide (1). In Curaçao, dengue is endemic with the co-circulation of the four viral serotypes (DENV-1 to -4)(2). The CHIKV and ZIKV caused an outbreak in 2014-2015 and 2016-2017, respectively (3). In the Caribbean, these vector-borne diseases (VBDs) are transmitted to humans by the bite of infected Aedes aegypti females mosquitoes (4). Preventing or reducing DENV, CHIKV, and ZIKV virus transmission depends entirely on controlling the mosquito population or interruption of human-vector contact. Factors that influence the rapid expansion of these VBDs are climate change, population growth, urbanisation, international travel and trade, lacking vector control infrastructure/services, and less developed health systems (5). VBDs pose substantial challenges to health systems in the countries they affect, especially resource-limited countries or Small Island Developing States (SIDS).

In the last decennium, much attention has been paid to health system strengthening because there has been a growing acknowledgement that a less developed health system is one of the main obstacles to overcome in order to achieve successful and sustainable public health interventions (6). The World Health Organisation (WHO) has developed a framework called "The health system Building Blocks" that aims to promote a common understanding of what a health system is and what constitutes health system strengthening (7). These building blocks define the health system's desirable attributes and offer a mechanism to recognise bottlenecks in structure and performance. A health system consists of all organisations, people, and actions (e.g., staff, funds, information, supplies, transport, communications, and overall guidance and direction) whose primary intention is to promote the system and restore or maintain health (7). The health system also delivers preventive, curative, and rehabilitative interventions through a combination of actions (8).

In the WHO framework, a health system is conceptualised as consisting of six building blocks: (1) leadership/governance; (2) health information system; (3) financing system; (4) health workforce; (5) medical products/vaccines/technologies; and (6) service delivery, as well as process elements (e.g., access, coverage, quality and safety), and outcomes (e.g., improved health and health equity, responsiveness, social and financial risk protection, and improved efficiency)(Fig. 1)(8). According to the WHO, the leadership/governance and the health information systems provide the basis for policy and regulation of all the other health system blocks (8). Leadership/governance involves ensuring a strategic policy framework, adequate oversight, attention to system design, and accountability. An efficient health information system ensures the production, analysis, dissemination, and use of reliable and timely information (7). A good financing system raises adequate funds in ways that people can use the needed services and are protected from impoverishment (7). A well-performing health workforce works in responsive, fair, and efficient ways to achieve the best health outcomes possible, given available resources and circumstances (7). A well-functioning health system ensures equitable access to essential medical products, vaccines, and technologies and ensures quality, safety, efficacy, and cost-effectiveness. Good service deliveries deliver efficient, reliable, quality personal and non-personal health interventions to those in need, wherever and whenever care is needed, with minimum waste of resources (7). Health system strengthening means improving the six building blocks mentioned above and managing their 
interactions in ways that achieve more equitable and sustained improvements across health services and health outcomes. Both technical and political knowledge and action are required (7).

The WHO framework is valuable because of its ability to provide a common language among experts and a good discourse structure on health system affairs (9). However, for applied research, it needs to be adapted and made context-specific (10). It has also been argued that the mechanical segmentation of effects by the WHO building blocks, without recognition of their interactions, inhibit the understanding of the system (10). Despite the shortcomings, the WHO building blocks framework has become the framework most often used to strengthen the health system. The WHO building blocks framework has been used to determine the overall performance of public healthcare facilities (11), implications of health sector reforms (12), and the baseline status of health facilities (13). Furthermore, it has been used to understand the impact of interventions or programs on the health system in the field of HIV/AIDS (14), malaria (15), measles, and polio (10).

The recent outbreaks of VBDs in Curaçao highlight the need to evaluate the performance of the health system. This qualitative study aims to examine the performance of the health system of Curaçao with regards to the prevention and control of VBDs in the last decennium by using the WHO health system building blocks. This aim will be addressed by assessing and evaluating the structure, organisation, functions, processes, and actions performed by the health system concerning the prevention and control of VBDs. The gained knowledge will be used to conceptualise actions to improve the performance of the health system. This study's findings highlight policy and implementation problems worthy of attention and suggest potential solutions to health system bottlenecks. Also, our findings may help better understand the interactions between the building blocks. This knowledge will lead to the strengthening of the health system of Curaçao for future epidemics of not only VBDs but also other infectious diseases (e.g., COVID-19). Furthermore, other SIDS can also benefit from our results and recommendations.

\section{Method}

\section{Study design}

This multi-method qualitative study is based on the interpretive paradigm and was performed from January 2019 to February 2020. The study was designed based on the theoretical framework of the WHO health system building blocks, and it was applied at the time of data collection, analysis, and result interpretation. A combination of different qualitative research methods was used to provide a confluence of evidence that breeds credibility. First, content analysis of governmental documents was carried out to understand the governmental structure more in-depth and to gain insights into all that was written (e.g., protocols, laws, and action plans) on prevention and control of VBDs in Curaçao. Information drawn from the content analysis was used to design topic guides for Focus Group Discussions (FGDs) and interviews with experts. Second, FGDs and interviews with experts were performed to gain insights into motivations, practices, and institutional issues as well as the experiences and perceptions of the workforce of the health system. Information drawn from the FGDs and interviews with experts was used to validate and 
support information drawn from the content analysis. Third, observations (e.g., observe house inspections performed by the vector control unit) were conducted to understand further institutional bottlenecks and the working procedure of the health system's workforce. The observations were used to validate and support the information drawn from the content analysis, FGDs, and interviews with experts.

\section{Study site}

In October 2010, the Netherlands Antilles (The Netherlands Antilles was a constituent country of the Kingdom of the Netherlands and consisted of several islands located in the Caribbean Sea) was dissolved, and Curaçao became an autonomous country within the Kingdom of the Netherlands. Curaçao is located $\pm 65 \mathrm{~km}$ north of the Venezuelan coast. The island has a surface area of $444 \mathrm{~km}^{2}$ and has a moderate tropical climate with two seasons (rainy and dry season), with an average temperature of 25$28^{\circ} \mathrm{C}$. According to the Central Bureau of Statistics of Curaçao, the estimated population was approximately 158665 inhabitants on January 1st, 2019 (16). There are different ethnic backgrounds, with an Afro-Caribbean majority and minorities such as Dutch, French, Latin American, South- and EastAsian, Portuguese and Levantine people (3). Papiamentu, Dutch, and English are the official languages of Curaçao, with Spanish also being widely spoken.

\section{Study population}

A total of five FGDs $(n=30)$ were conducted with professionals that have worked for the Ministry of Health, Environment, and Nature of Curaçao (GMN). Three of the five FGDs were conducted with professionals that have worked in the vector control unit (VCU), one was held with previous ministers of health, and one with health professionals that have worked in the policy, communication, vector control, and Epidemiology and Research (E\&R) department. Interviews were conducted among eleven experts. The characteristics of the study population are presented in Table 1. The number of FGDs and interviews with experts were determined after data saturation, where information starts to repeat itself, had been reached. Study participants were recruited using key informants such as heads of departments, and experts were chosen based on their characteristics such as experience and knowledge. All participants signed a written informed consent. The study sample is well represented by professionals from all the six WHO building blocks analysed in this paper. 
Table 1

Characteristics of the study participants

\section{Focus Group Discussion with Professionals $(n=30)$}

\section{Number of Age Gender* Expertise (s) \\ participants range}

$1525-\quad 5 F / 4 M \quad$ Vector control, surveillance of vector

61

$2626-\quad 2 F / 4 M \quad$ Vector control, surveillance of vector and breeding sites

$\begin{array}{llll}3 & 3 & 47- & 2 \mathrm{~F} / 1 \mathrm{M}\end{array} \quad$ Previous ministers of health

$45 \quad 57-\quad 1 F / 4 M \quad$ Epidemiology, vector control, policy, surveillance of cases, vector and breeding sites, microbiology, laboratory techniques, and procedures, entomology, microbiology

$57 \quad 36-\quad 4 F / 3 M \quad$ Vector control, surveillance of vector

63

\section{Expert Interviews $(n=11)$}

Name $^{+} \quad$ Age Gender Profession (s)

$\begin{array}{lllll}1 & \text { Sarah } & 59 & \text { F } & \text { Epidemiologist } \\ 2 & \text { John } & 59 & \text { M } & \begin{array}{l}\text { Previous head of the sector of health/ epidemiologist/ } \\ \text { general practitioner }\end{array}\end{array}$

3 Elsa $\quad 52 \quad \mathrm{~F} \quad$ Entomologist/ policymaker/ registered restricted pest controler

\begin{tabular}{|c|c|c|c|c|}
\hline 4 & Ana & 63 & $\mathrm{~F}$ & Coordinator of the VCU** \\
\hline 5 & Peter & 62 & $M$ & Coordinator of the VCU \\
\hline 6 & Stephan & 57 & $M$ & $\begin{array}{l}\text { Policy-maker/ general practitioner/ previous director of the } \\
\text { sector of health }\end{array}$ \\
\hline
\end{tabular}

7 Glen $\quad 66 \quad M \quad$ Previous minister of health/ general practitioner

8 Sol $\quad 69 \quad$ F $\quad$ Geriatrician

9 Audrey NA F Laboratory technician

10 Twin $\quad 81 \quad \mathrm{~F} \quad$ Alternative medicine practitioner

11 Sandro $\quad 66 \quad M \quad$ General practitioner

+ Fictional names were used to protect the identity of the study participants.

* $\mathrm{F}=$ Female, and $\mathrm{M}=$ Male.

$\star \star \mathrm{VCU}=$ vector control unit 


\section{Data collection}

\section{Content analysis}

Downe-Wambolt defines content analysis as "a research method that provides a systematic and objective means to make valid inferences from verbal, visual, or written data in order to describe and quantify specific phenomena." (17). In health sciences, content analysis as a method has been employed to achieve different aims, for example, to evaluate health campaigns (18), or to determine the main challenges of processes related to health service (19). In this study, the content analysis of documents (e.g., reports, protocols, images, radio, and television spots) was conducted first because it provides data on the context within which the study participants and departments had operated during the outbreaks of VBDs. Thus documents bear witness to past events (e.g., conducted vector control interventions), provide a means of tracking change and development, and highlight the conditions that influence the phenomenon under investigation (20). The following inclusion criteria were applied: (I) the document is original, (II) it is related to DENV, CHIKV, and ZIKV, and (III) it was developed and used by governmental officials within the following timeframe, January 1, 2010-February 28, 2020. This timeframe includes the last massive outbreak of DENV infection in 2010/2011 and the CHIKV and ZIKV infections outbreaks in 2014-2015 and 2016-2017, respectively. The following exclusion criteria were applied to the documents: (I) the document has no publication date and author details, and (II) it is not related to governmental actions with regards to prevention and control of DENV, CHIKV, and ZIKV. After correcting for irrelevant or repetitive documents, a total of 50 items were included in the content analysis. An overview of the items used in the content analysis of documents is presented in Table 2.

Table 2

Characteristics of the collected documents.

\begin{tabular}{|c|c|c|c|}
\hline & Type of document & Amount & Department \\
\hline 1 & Legislation, policy, protocols & 4 & Policy Department \\
\hline 2 & $\begin{array}{l}\text { Plans (e.g., project, business, and } \\
\text { Surveillance, communication, plan) }\end{array}$ & 13 & $\begin{array}{l}\text { Director of the health sector, Policy } \\
\text { Department, Department of E\&R }\end{array}$ \\
\hline 3 & Health promotion materials & 14 & Department of communication \\
\hline 4 & Evaluation reports & 4 & $\begin{array}{l}\text { External medical entomologists, Court of } \\
\text { Audit Curaçao (Algemene Rekenkamer } \\
\text { Curaçao) }\end{array}$ \\
\hline 5 & Minutes of meetings & 5 & $\begin{array}{l}\text { Director of the health sector, Policy } \\
\text { Department, Department of E\&R, VCU }\end{array}$ \\
\hline 6 & Budget of GMN & 2 & Policy Department \\
\hline \multirow[t]{2}{*}{7} & Surveillance reports & 8 & Department of E\&R, VCU \\
\hline & Total documents & 50 & \\
\hline
\end{tabular}




\section{Focus group discussions and interviews with experts}

Five FGDs and eleven interviews with experts were conducted in the second phase of data collection. As mentioned above, FGDs and interviews with experts were performed to gain insights into their motivations, practices, experiences, and perceptions with regards to the performance of the health system of Curaçao during the outbreaks of VBDs. Also, institutional issues drawn from the content analysis of documents were discussed more in-depth during the FGDs and interviews with experts. The topic guides were semi-structured to cover the six health system building blocks and the health system bottlenecks that were drawn from the content analysis of documents (See Additional files 1-6: Topic guides for FGDs and interviews with experts). The topic guides were piloted and adjusted before the data collection. The FGDs and interviews were conducted in Papiamentu or Dutch, recorded, and transcribed.

\section{Observations}

Based on the information collected during the interviews and the FGDs with health professionals, we conducted five follow-up observation sessions during inspections of the VCU to verify reported data related to prevention and control measures and their related challenges. The VCU organised six training sessions with regards to mosquito species in Curaçao, prevention and control of mosquito-borne diseases. We participated in these training sessions to determine the knowledge and entomological skills of the workforce of the VCU. Also, presented challenges of the workforce were recorded. Furthermore, we participated in four meetings organised by the VCU, GMN, and the department of risk communication (RC) and E\&R to observe how departments collaborate to work on international health regulations, RC, prevention and control of VBDs. The observations were recorded as notes and pictures. One observer and one note-taker conducted the observation sessions. The collected information was compared at the end of each observation session to identify potential discrepancies. Additional observation sessions were conducted to clarify these differences and reach common conclusions.

\section{Data analysis}

The data coming from FGDs and interviews with experts were analysed using different codes, which refer to an idea, issue, topic or opinion evident in the data. Some of the codes were raised by the study participants themselves (inductive). In contrast, others were prompted by the interviewers using topics in the interview guide that were derived from literature and existing theories (deductive). We employed two cycles of inductive and deductive coding. In the first cycle, codes were used when analysing FGDs and interview with experts. These codes were assigned to 10 categories, which were analysed in the second cycle of analysis. The following categories were identified; (I) Leadership/Governance, (II) Financing system, (III) Medical products and technologies, (IV) Health information system, (V) Workforce, (VI) Service delivery, (VII) Trust, (VIII) Prevention, (IX) Evaluation, and (X) Recommendation (Additional file 7: Table 1. Coding list). The analysis of the content of documents and observations was as follow: first, all text was read several times to familiarise with the content. Second, data from the content analysis of documents and observations were coded using the coding list used for the FGDs and interviews with experts. The same coding list was used because it offered the opportunity to link and compare the data. 
This data analysis method facilitated the data interpretation to elicit meaning, compare data, gain understanding and develop empirical knowledge. The data was analysed using Nvivo (version 12 Pro). All quotes in the current research were transliterated to keep the context intact.

\section{Results}

The results are presented here by the following key themes; leadership/governance, health information system, financing system, health workforce, medical products and technologies, and service delivery. Each paragraph starts with a structural bottleneck and ends with its implication on the health system's performance. Reported names in the result section are pseudonym names.

\section{Leadership/Governance}

It is essential to understand the organisational structure of the GMN, to understand each department's responsibilities with regards to the prevention and control of VBDs. The organisational structure of the GMN is illustrated in Fig. 2. In the case of the prevention and control of zoonotic diseases, the policy department is responsible for making laws for the Department of Technical Hygiene and Care (THZ), which is part of the Department of Medicine and Health Affairs (G\&Gz), and THZ is responsible for the implementation and enforcement of the laws (Curaçao: Business plan, Ministery of Health, Environment and Nature, pg: 10-11). Different experts have confirmed the mentioned task division. However, at the same time, they indicated that the mentioned departments do not perform their tasks as it is documented. Also, they indicated that the collaboration between the policy department and other departments of the $\mathrm{GMN}$ is minimal. The following quote portrays this issue:

Moderator: Okay, there is no law or protocol?

Female 1: No, look.

Male 2: We met a few times.

Female 1: Yes, but with the dengue team (microbiologist, head of the THZ, entomologist, epidemiologist, medical doctors, communication expert).

Male 2: The team never received feedback. There was no feedback.

Female 1: We asked for the protocol every time. Yes.

Male 1: Look, the process to develop a law/protocol is not clear for us (policymakers working for the policy department) neither. We complained many times about this issue within the department. The problem remains the same. Again the departments that work in the field know the content of their work; they are the experts, not someone that sits in the policy department. The policymakers working for the policy department need to guide the departments to develop their protocols/law/guidelines, but the content needs to come from the departments, and this is not happening.

- FGD with health professionals working for the GMN

Insufficient collaboration causes issues such as the development of laws/protocols/guidelines for preventing and controlling VBDs to fall short on certain ends. This issue has been confirmed by notes 
derived from meetings organised by different departments which are part of the G\&Gz. The following observation note portrays this issue:

The RC department organised a meeting to discuss a health promotion campaign for mosquito-borne diseases in Curaçao. The meeting included professionals from different departments, such as the VCU and the E\&R department. When the topic "collaboration" was introduced, one of the health professionals asked permission to express her concern.

She was not happy and showed signs of frustration. For example, she tapped her fingers and scratched the back of her head. When she got permission to speak, she said the following: "We have a policy department, but the professionals working for this department do not know what they need to do. The "real" professionals are working for the departments that are responsible for the implementation of the law/policy. It does not make sense. There is no collaboration between the policy department and the departments that are responsible for the implementation of the law. That is why there is no law."

The other health professionals agreed with her statement by saying: "You are right" or "Exactly" or "I could not agree more".

At that moment, everybody started to talk, and the moderator of the meeting had no control over the invited health professionals. It looked like everybody was not happy with the current collaboration.

-Observation notes of a meeting held on October 22, 2018 (G\&Gz).

Data drawn from FGDs and interviews with experts revealed that the collaboration between departments is lacking because the workforce's work procedure is not documented in any policy or law. Two evaluation reports confirmed the fact that there is no overall strategic policy framework that guides departments during outbreaks of infectious diseases. There is a range of laws, technical briefs and plans that address the prevention and control of VBDs; however, these laws/plans have their shortcomings. There is a law on infectious diseases (verordering bestrijding van besmettelijk ziekten P.B.1921, no 61), which has been used to guide the prevention and control of new infectious diseases, such as dengue, chikungunya, and Zika. However, its usability was questioned in two evaluation reports and by different experts. The evaluation reports and interviewed experts indicated that the law is out-dated since it was created in 1921. Also, the law does not contain information concerning the work procedure and responsibilities of needed professionals, departments, and organisations to prevent and control infectious diseases. These shortcomings obstruct collaboration, oversight and accountability within the health system of Curaçao.

A regulatory law on pesticides (Landsverordering bestrijdingsmiddelen P.B. 1961, no 116) was introduced in 1961 by the government of the Netherlands Antilles. This law addresses rules for the import and use of insecticides; however, it does not address the safe use of insecticides and their application in nature. Data that was drawn from an evaluation report written by two external medical entomologists in 2016 confirmed this issue. More recently, a local medical entomologist explained that since there is no regulation on the safe use of insecticides and application in nature, private and governmental pest controllers can and are using insecticides that have a damaging effect on our environment (e.g. water, soil, air, animals, plants, and other non-target organisms) without prosecution. The workforce of the VCU 
stated that the reported lack of regulations concerning the safe use of insecticides and their application in nature weakens the authority and control mechanism of the health system. Both external and local medical entomologists reported that the existing law on pesticides had not been updated or revised since 1961 by the government of the Netherlands Antilles or Curaçao.

A large number of participants reported that the organisational structure of the GMN introduced after October 2010, thus when the Netherlands Antilles was dissolved and Curaçao became an autonomous country within the Kingdom of the Netherlands, it was just copied from the one from the Netherlands. This process took place without taking the workforce's capacity or cultural, financial and social factors of Curaçao into account. All the interviewed ministers of health and the majority of the interviewed experts indicated that the organisational structure of the GMN is weak and observed that its deterioration would continue if the system is not adequately evaluated and adjusted. The following quote portrays this issue:

Data that was drawn from an evaluation report and observation notes confirmed the reported deterioration of the health system. Other collected data related to this theme revealed that this organisational problem causes issues such as inadequately task and power division, and it affects how decisions are made and activities are carried out negatively.

We found that lack of documentation (e.g., agreements) and collaboration between departments obstruct policymaking and the health system's management. Experts indicated that most of the agreements concerning VBDs were made verbally and were not documented during the outbreaks. Only one document (Integrated Management Strategy for Dengue Prevention and Control in Curaçao, 2012) was found that contains agreements made by a multidisciplinary team with regards to the prevention and control of DENV infection. The reported lack of documentation has been discussed and confirmed by an evaluation report that addresses prevention and control measures performed by the GMN during the CHIKV infection epidemic. We found that the lack of documentation leads to delays in key processes or holds up projects, restricts collaboration, loss of data, communication gaps, uninformed decisions and lack of transparency.

Besides the issue with regards to documentation, collaboration to develop a policy/plan/protocol is minimal, according to different experts. Experts working for the E\&R, VCU, and the policy department indicated that there was a plan (Project plan: Breeding sites elimination and cleaning action Curaçao, November 2014) that addresses the prevention and control of the Ae. aegypti mosquito during the CHIKV infection epidemic. However, this plan was made without their collaboration, and it was not shared within the health system. The performed document analysis has verified the existence of this plan, and the performed interviews with experts and FGDs have highlighted the fact that only one participant, which is the maker of the plan, was aware of the plan's content. The mentioned plan only focuses on a public health campaign conducted during the CHIKV infection epidemic. It describes a part of the task of the VCU, Selikor (a governmental organisation assigned to perform waste management) and an assigned organisation that focussed on clearing streets. However, relevant

Page 11/35 
departments/organisations/professionals such as the E\&R, general practitioners, laboratories are not mentioned, and an extended description of the multidisciplinary collaboration is not present in the mentioned plan. The reported lack of documentation and collaboration cause frustration among coworkers. The following quote portrays this issue:

Male 1: But explain this to me, so you have made a plan/protocol for the VCU?
Male 3: Yes.
Male 1: For vector control?
Male 3: Yes.
Male 1: Where is it now?
Male 3: I do not know; the general secretary has it now.
Male 1: But you can not say that. The management team needs to approve it first. Did you discuss this with the management team?

Male 3: I do not know. Who is part of the management team?

Male 1: The general secretary (SG), director of the sectors (SD) and the director of the policy department are members of the management team. However, nobody else from the ministry of health (e.g. epidemiology) has received this plan?

Male 3: I do not know.

Female 1: I am glad that this group discussion is being recorded. In front of all my colleagues here, he said that he made a protocol for the VCU. A few minutes ago, we spoke about the importance of collaboration and that we need to work together, and look, he worked again on his own.

Male 1: He made it on its own, again! Moreover, he is implementing his protocol.

Moderator: So this is an excellent example?

Male 1: Yes.

-FGD with health professionals working for the GMN

The quote above portrays how separated, in a siloed manner, the employees of the GMN work from each other. Besides this, interviewed experts indicated that leadership skills and knowledge with regards to VBDs among the personnel with functions of leadership are insufficient. This issue obstructs guidance and collaboration to develop protocols for the prevention and control of VBDs. For example, obtained data collected from documents and interviews with experts highlighted the fact that policies/protocols/plans (e.g., surveillance of microcephaly or pregnant women) were also lacking during the Zika epidemic.

\section{Health information system}

Data that was drawn from this qualitative study highlighted the following challenges regarding the collection, analysis and dissemination of information concerning VBDs within and outside the health system of Curaçao. 


\section{Challenges associated with entomological practices}

Experts indicated that the VCU, which is responsible for collecting information related to mosquitoes and their breeding sites, has been facing challenges to recruit and maintain professionals with the capacity to collect entomological data. This challenge, in turn, obstructs the data collection on local mosquito fauna. A report written by two external medical entomologists confirmed this statement. Table 3 presents published data concerning mosquito species of Curaçao. 
Table 3

List of mosquito species of Curaçao.

\begin{tabular}{|c|c|c|c|c|c|c|}
\hline & Species & $\begin{array}{l}\text { Host } \\
\text { preference }\end{array}$ & Status & Reported & Pathogens & Reference \\
\hline 1. & $\begin{array}{l}\text { Anopheles } \\
\text { pseudopunctipennis }\end{array}$ & Mammals & Native & 1949 & Malaria parasites & $\begin{array}{l}\text { Van der } \\
\text { Kuyp, } \\
1949\end{array}$ \\
\hline 2. & Aedes aegypti & Human & Native & 1949 & $\begin{array}{l}\text { Dengue, Zika, } \\
\text { chikungunya virus, } \\
\text { Dirofilaria immitis }\end{array}$ & $\begin{array}{l}\text { Van der } \\
\text { Kuyp, } \\
1949\end{array}$ \\
\hline 3. & $\begin{array}{l}\text { Aedes } \\
\text { taeniorhynchus }\end{array}$ & $\begin{array}{l}\text { Mammals, } \\
\text { birds, } \\
\text { reptiles }\end{array}$ & Native & 1949 & $\begin{array}{l}\text { Eastern equine } \\
\text { encephalitis virus } \\
\text { (EEE), Venezuelan } \\
\text { equine encephalitis } \\
\text { virus (VEE), } \\
\text { Dirofilaria immitis }\end{array}$ & $\begin{array}{l}\text { Van der } \\
\text { Kuyp, } \\
1949\end{array}$ \\
\hline 4. & $\begin{array}{l}\text { Haemagogus } \\
\text { chrysochlorus }\end{array}$ & Mammals & Native & 1949 & - & $\begin{array}{l}\text { Van der } \\
\text { Kuyp, } \\
1949\end{array}$ \\
\hline 5. & $\begin{array}{l}\text { Psorophora } \\
\text { confinnis }\end{array}$ & Mammals & Native & 1949 & VEE virus & $\begin{array}{l}\text { Van der } \\
\text { Kuyp, } \\
1949\end{array}$ \\
\hline 6. & Culex maracayensis & - & Native & 1949 & - & $\begin{array}{l}\text { Van der } \\
\text { Kuyp, } \\
1949\end{array}$ \\
\hline 7. & Culex nigripalpus & $\begin{array}{l}\text { Mammals, } \\
\text { birds, } \\
\text { reptiles, } \\
\text { batrachians }\end{array}$ & Native & 1949 & $\begin{array}{l}\text { Saint Louis } \\
\text { encephalitis virus } \\
\text { (SLE), EEE virus }\end{array}$ & $\begin{array}{l}\text { Van der } \\
\text { Kuyp, } \\
1949\end{array}$ \\
\hline 8. & $\begin{array}{l}\text { Culex } \\
\text { quinquefasciatus }\end{array}$ & $\begin{array}{l}\text { Mammals, } \\
\text { birds }\end{array}$ & Native & 1949 & $\begin{array}{l}\text { West Nile virus } \\
(\text { WN), Dirofilaria } \\
\text { immitis, Lymphatic } \\
\text { filariasis }\end{array}$ & $\begin{array}{l}\text { Van der } \\
\text { Kuyp, } \\
1949\end{array}$ \\
\hline 9. & Culex erraticus & $\begin{array}{l}\text { Mammals, } \\
\text { birds, } \\
\text { reptiles }\end{array}$ & Native & 1949 & EEE, VEE virus & $\begin{array}{l}\text { Van der } \\
\text { Kuyp, } \\
1949\end{array}$ \\
\hline 10. & $\begin{array}{l}\text { Deinocerites } \\
\text { magnus }\end{array}$ & $\begin{array}{l}\text { Mammals, } \\
\text { birds, } \\
\text { reptiles }\end{array}$ & Native & 1949 & - & $\begin{array}{l}\text { Van der } \\
\text { Kuyp, } \\
1949\end{array}$ \\
\hline 11. & $\begin{array}{l}\text { Wyeomyia } \\
\text { celaenocephala }\end{array}$ & Mammals & Native & 1949 & & $\begin{array}{l}\text { Van der } \\
\text { Kuyp, } \\
1949\end{array}$ \\
\hline
\end{tabular}

Adapted from Surveillance and control of vector species in Curraçao (West Indies): Situation analysis an needs assessment, by Francis Schaffner and Marieta Braks, 2016. Adapted with permission. 
Both the report and some experts agreed on the fact that information concerning local mosquito fauna is scarce and considered to be old (from the late 1940s). A local medical entomologist elaborated further on this topic and reported six more species (Aedes infirmatus, Aedes sollicitans, Aedes triseriatus, Aedes vexans, Coquillettidia perturbans, Aedes condolescens) that need to be added to the list. However, the presence of these additional species needs to be confirmed. The workforce of the VCU also confirmed this reported lack of information concerning the local mosquito fauna. They stated that the surveillance and documentation of mosquitoes species have deteriorated in the last ten years, and currently, it is nonexistent. The following quote portrays this issue more in-depth.

Moderator: Okay, let's continue with the next topic. We spoke about the
problem with regards to documentation. The steps that need to be taken
are not clear. We spoke about the challenges that departments of the
government had during the epidemics. We spoke about laws and structure.
Let us talk about surveillance, surveillance of the vector. Can you describe
how surveillance of mosquitoes was performed during the epidemics? And
currently? Do we monitor mosquito species present in Curaça, and do we
test the mosquitoes to check for viruses?
Male 4: What do you mean? The control that we are performing now?
Moderator: No, I am talking about the surveillance of the vector, not vector
control. For example, the department of E\&R is responsible for the
surveillance of cases of VBDs, and the VCU is responsible for the surveillance
of the mosquitoes.
Male 4: Look, we had a surveillance system, but currently, we are not
monitoring mosquitoes because we do not have the means to do it. We
need to create a structure for the surveillance of mosquitoes in order to
have continuity. I mentioned this in the policy that I made for the VCU.
Moderator: Thus, currently, there is no surveillance of mosquitoes?
Male 4: No, there is no surveillance of mosquitoes. We are using old
information and data that you (PhD students) are currently collecting.
-FGD with health professionals working for the GMN

Since there is no ongoing surveillance of mosquitoes, there is no monitoring of the insecticide resistance status of Aedes populations. This leads to minimal dissemination of information concerning the vector of dengue, chikungunya and Zika virus within the health system. 


\section{The reliability of collected entomological data}

Some experts have questioned the analysis, interpretation, and entomological data usage. According to an evaluation report, the department of E\&R analyses collected data concerning larvae and pupae to determine entomological indices (e.g. household index, container index) for the VCU. Interviewed experts working for the E\&R department have reported this written task division and reported that the analysis of the mentioned data happened once. The data was collected in 2015 (not the entire year) by the VCU, and it was analysed in 2016. Experts working for the E\&R department elaborated further on this issue and reported that the data analysis was obstructed because the collected data was not reliable since it was collected by a workforce with limited capacity concerning entomological field techniques. Data that was drawn from the FGDs and interviews with experts revealed that the lack of entomological information affects the performance of VCU negatively because changes in geographical distribution and density of the vector are not taken into account to guide vector control strategies. Also, this missing data obstructs the evaluation and adjustment of vector control strategies, which, in turn, negatively affects decisionmaking processes.

\section{Challenges associated with surveillance systems}

Some experts have also questioned the surveillance systems (laboratory and syndromic surveillance system) that the E\&R department uses to detect the presence and activity of VBDs in Curaçao. Data that was drawn from this qualitative study highlighted the following two critical bottlenecks which obstruct the surveillance of cases of VBDs

1. Delays in disseminating information: The timeframe to report the laboratory-confirmed cases to the department of E\&R has extended enormously in the last five years. Delays in disseminating information concerning laboratory-confirmed cases could have caused delays in detecting the onset of VBDs in Curaçao. The following quote portrays this issue:

2. The surveillance system's sensitivity: Several experts have stated that prevention and control actions to combat the CHIKV infection outbreak started late. One expert indicated that the syndromic surveillance system was not sensitive enough to detect the CHIKV infection outbreak's onset. The epidemiologist responsible for the surveillance system during the outbreak of CHIKV infection concluded in late 2014 that the method (mean incidence) used to identify the outbreak of CHIKV infection was indeed less sensitive than the Endemic Channel method. The Endemic Channel method was introduced during the CHIKV infectious outbreak (beginning 2015); this method uses the previous seven years' surveillance data (e.g., fever as a proxy for some VBDs) to determine three levels of thresholds. These cut-offs would allow the epidemiologist to identify how the current incidence would relate to past data, indicating if the observed incidence is below expected (success), as expected (safe) or higher than expected (alert). The Endemic Channel method has proven to be more suitable to detect outbreaks in small countries with small data sets. This statement has been confirmed with the information illustrated in Fig. 3. 
Despite the information from PAHO/WHO alerting all countries of the Americas, these two bottlenecks could be possible explanations for the reported delay in detecting the onset of the CHIKV infection outbreak. The reported delay in detection of the onset of the CHIKV infection outbreak might have obstructed the response of the department of E\&R to inform needed stakeholders (e.g. GPs, VCU, communication department, laboratory etc.) to start with actions related to the prevention and control of VBDs.

\section{Challenges associated with disseminating information}

All interviewed experts and participants of the FGDs indicated that the dissemination of information within the health system and to the community or other stakeholders was minimal during the last three epidemics of VBDs, especially during the CHIKV infection outbreak. For example, GPs, an important stakeholder group, have stated that the communication between the government and them needs to be improved because limited instructions and updates were offered during the outbreaks. Also, it has been stated that information with regards to VBDs did not reach every GP. The following quotes portray the mentioned communication problems

"GP: I think that the flowchart of information needs to be improved. Look, the national epidemiologist reaches a specific group of GPs that are members of the association of GPs. It is always the same GPs that are present during presentation and meetings organised by the association. For example, when you go to meetings organised by the association, about 40 of the $100 \mathrm{GPs}$ are present. Thus, there is a group that you are not reaching.

Interviewer: That is a piece of useful information.

GP: For example, in most cases, GPs who speak Spanish are not present: thus, they are a group that is difficult to reach. Also, with e-mails.

Interviewer: Do you notice that fewer Spanish-speaking GPs attend the meetings?

GP: Yes, they are doing their best to change how they share information. The information is shared in Papiamento or English. However, English can be challenging to understand."

-Sol, geriatrician

It is interesting because many people were tested without no valid reason, like old females. Why? Was the protocol not clear for the GPs?

-Sarah, epidemiologist

GP: In the case of CHIKV infection, I had the idea that the GPs were confused; the recommendations were not concrete, testing or no testing? I think the capacity to test was limited. I am not sure about the problem, but the recommendations were not clear. The community was sick, and it was challenging to contact $G \& G z$. I called a few times to ask for advice.

-Sol, geriatrician

Communication problems within and outside the health system have been discussed in different documents; for example, in an evaluation report, written by the "Court of Audit Curaçao", entitled "Report Chikungunya" and observation notes of meetings organised by the workforce of the health system. The evaluation report mentioned above confirmed the reported lack of communication between stakeholders, 
including GPs, and highlighted that the absence of a communication strategy plan obstructed communication between the stakeholders during the outbreak of CHIKV infection.

\title{
Financing system
}

A good financing system raises adequate funds to invest in the prevention and control of diseases. The method used to raise funds for the departments responsible for preventing and controlling VBDs has been discussed in five documents (2 evaluation reports, the budget of the GMN 2019-2022, and two observation notes) FGDs and interviews with experts. We could not locate and review the assigned budget to prevent and control DENV, CHIKV and ZIKV infection outbreaks. Lack of documentation could explain why we did not get an overview of the budget and the expenses related to the prevention and control of the mentioned VBDs.

A budget made for 2019-2022 was obtained, and it indicates funds that are meant to be available for the prevention and control of VBDs. For example, 25.000 NAF (Antillian Guilders) ( \pm 13.740 USD, 1 USD $=1.82$ NAF) was available for detection and control of pest, mosquito and other insects (e.g. the use of insecticide or pesticide), 50.000 NAF ( \pm 27.470 USD) for health promotion, including RC, $50.000 \mathrm{NAF}$ for the training of the workforce of the THZ, 25.000 NAF for purchase of machines and $7.500 \mathrm{NAF}( \pm 4120$ USD) for other materials (e.g. uniforms, gloves etc.). These amounts were budgeted for 2019, 2020, 2021, and 2022 respectively. This budget was presented and discussed during FGDs and interviews with experts; remarkably, most interviewees never saw this budget. Data that was drawn from these interviews/discussions indicated that a critical bottleneck in the financing system is the manner to make the budget for the departments of the GMN. Some experts stated that during the CHIKV infection outbreak, the budget of the departments of GMN was made by a government official with authority. The budget was never presented or discussed with the involved departments. The following quote portrays this issue:

\begin{abstract}
"Male 1: Yes, what he needs to do is, talk with the heads of departments every year, to plan, to know what the departments need to function. Ask what they need for the next year? How much personnel is needed? Materials? Talk about these factors and develop a budget. He added all the expenses together, for example, health promotion materials and came with a budget for all departments. He needs to explain how much each department needs for health promotion and give each department their money when it is needed. That is what he needs to do, but this never happened.
\end{abstract}

Male 2: He needs to respect the budget too.

Female 1: Yes, respect it because currently, they are using the budget of one department to cover financial issues of another department."

-FGD with health professionals working for the GMN

The reported lack of collaboration in drafting the budget of GMN leads to a budget that is not realistic and suitable to cover the expenses of the involved departments during the epidemics. For example, a policymaker indicated that during the ZIKV infection epidemic, 50.000 NAF was available for health promotion; however, the actual expenses were $150.000 \mathrm{NAF}( \pm 82.420 \mathrm{USD})$. The presented budget for 2019-2022 also confirmed the fact that the budget does not take economic inflation into account 
because the same amount of money has been budgeted for each year. Besides, both an evaluation report and the majority of interviewed experts indicated that the funds allocated for specific expenses (e.g. working materials, training, etc.) are not available when needed. The workforce of the VCU elaborated further on this topic and stated that due to limited financial support, there were limited materials (e.g. insecticide), personnel, and training for personnel during the outbreak of CHIKV infection. The following quotes portray this issue: 
"Male 2: There was no workforce at that moment.

Female 2: Workforce, there was no personnel to perform control of mosquitoes.

Male 2: We need to blame the government again. Workforce, because it is not possible that you have a country and there are no inspectors to perform vector control.

Female 4: Yes.

Moderator: Thus, when the CHIKV infection outbreak started, there were no inspectors to perform vector control?

Male 2: No, nobody.

Female 4: No.

Moderator: Thus, you looked for personnel during the epidemic of CHIKV infection?

Male 2: Yes.

Female 4: Twenty kids, twenty young people.

Female 2: Educated fieldworkers that worked for the GMN retired, and new employees have not been recruited."

-FGD with the workforce of the VCU

"Male 1: We need uniforms; my white shirt is almost brown now.

Female 3: Our badges expired long ago."

-FGD with the workforce of the VCU

"Moderator: You are working now with Abate?

Male 1: Yes.

Moderator: Do you have the possibility to wash your hands after using Abate?

Male 1: No.

Female 2: That is what he explained.

Female 1: We got a handsanitiser to disinfect our hands.

Male 1: No mask or gloves were given. We need to supply ourselves with what we need.

Female 1: Nothing was given to us."

-FGD with the workforce of the VCU

Remarkably, funds are being allocated for the prevention and control of VBDs. However, it is not being used as planned in reality or does not cover the actual expenses. Experts stated that the performance of departments (e.g. $\mathrm{VCU}$, communication, E\&R, etc.) has deteriorated due to the budget retrenchments that happened in the last two decades. No investments were made to maintain the capacity and quality of vector control, research, and communication practices. Previous ministers of health have confirmed this issue, and according to one interviewed minister, the government needs to change its approach to deal 
with the health sector, especially with prevention. The government does not see its expenses as investments to improve the health sector. This mindset leads to more budget retrenchment.

\section{The health workforce}

The Business plan of the Ministery of Health, Environment and Nature (2011-2014) provides information concerning the required formation for a well-functioning unit to prevent and control zoonotic diseases in Curaçao. This estimated formation has been compared with the available workforce during the epidemics of VBDs (Table 4). After comparing this information, it can be stated that the departments (Fig. 2) (e.g. the department of policy and Medicine and Health Affairs, including the communication, VCU and E\&R department) responsible for the prevention and control of VBDs are understaffed. For example, according to the Business plan, the department of E\&R needs nine full-time employees (FTEs)(Table 4). However, during the last three epidemics, the department of E\&R consisted of three employees; one medical doctor/ epidemiologist (1 FTE) and two other health professionals specialised in epidemiology and public health (2 FTEs). Data that was drawn from three reports, interviews with experts, and previous ministers of health has confirmed this issue. 
Table 4

The workforce during the epidemics in comparison with the required workforce to perform prevention and control strategies with regards to VBDs.

\begin{tabular}{|c|c|c|}
\hline Departments & $\begin{array}{l}\text { The estimated workforce } \\
\text { (The business plan of the GMN) }\end{array}$ & $\begin{array}{l}\text { The available workforce during } \\
\text { the epidemics of VBDs }\end{array}$ \\
\hline \multirow[t]{7}{*}{$\begin{array}{l}\text { Epidemiology } \\
\text { and Research }\end{array}$} & 1 head of the department & \multirow{7}{*}{$\begin{array}{l}1 \text { medical doctor/ epidemiologist } \\
\text { (head of the department) } \\
2 \text { health professionals specialised } \\
\text { in epidemiology and public health }\end{array}$} \\
\hline & $\begin{array}{l}2 \text { medical doctors specialised in } \\
\text { epidemiology }\end{array}$ & \\
\hline & 1 social scientist & \\
\hline & 1 economist specialised in health care & \\
\hline & 1 statistician & \\
\hline & 1 medical expert in environmental science & \\
\hline & $\begin{array}{l}2 \text { employees to support the management of } \\
\text { the department }\end{array}$ & \\
\hline Total FTE & 9 & 3 \\
\hline \multirow[t]{5}{*}{ VCU } & 1 head of the department & 2 coordinators \\
\hline & 15 vector inspectors & 20 fieldworkers \\
\hline & \multirow[t]{3}{*}{1 secretary } & 3 vector inspectors \\
\hline & & 1 secretary \\
\hline & & 1 administrative assistant \\
\hline Total FTE & 17 & 23 \\
\hline \multirow[t]{2}{*}{ Communication } & \multirow[t]{2}{*}{4 communication experts } & 2 communication experts \\
\hline & & 1 head of the department \\
\hline Total FTE & 4 & 3 \\
\hline \multirow{5}{*}{$\begin{array}{l}\text { Policy } \\
\text { department }\end{array}$} & 1 head of the department & 1 head of the department \\
\hline & 1 lawyer & 1 medical doctor \\
\hline & 2 researchers & 1 statistician \\
\hline & \multirow{2}{*}{$\begin{array}{l}8 \text { policy officers (4 for health care, } 3 \text { for } \\
\text { public health, and } 1 \text { for veterinary public } \\
\text { health) }\end{array}$} & 1 health scientist \\
\hline & & 1 health promoter \\
\hline Total FTE & 12 & 5 \\
\hline
\end{tabular}


As shown in Table 4, and according to an evaluation report (written by two external medical entomologists) and observation notes from 2013-2018 (during outbreaks of CHIKV and ZIKV infection), there was no head of the department, entomologist, nor any employee able to identify mosquitoes to species level. Besides, the field workers of the VCU went through several renewals of their contract because they have short-term employment contracts. These issues (lack of educated personnel, guidance, and continuity of prevention and control measures) have been discussed and confirmed by the field workers of the VCU during organised FGDs. The field workers elaborated further on this topic and stated that the insecurities with regards to their contracts reduce their motivation to perform their duties. Also, the majority of the field workers feel that they are being used and are not valued. The following quotes portray concerns of the field workers:

\footnotetext{
"Male 1: We got more things to do and what happened is that our work got mixed-up. That is the reason why I told my coordinators that they are using us. We, as field workers, are being used. We are here to prevent and control mosquitoes; thus, we need to work only with mosquitoes. We cannot work with all types of vectors because we do not have the education. We need to stand up and say we came here to work with mosquitoes.
}

Moderator: Okay.

Male 1: That is what we need to do."

-FGD with the workforce of the VCU

"Female 1: Look, the field workers that are working for the VCU are not inspectors specialised in vector control. I know that you are recording, but this is the truth. They are not inspectors.

Interviewer: I understood that they are not inspectors for vector control, but they have worked with different types of vectors.

Female 1: Yes, they are not educated, inspectors. They are being used as a shield, and that is the problem. It is criminal because the government creates a false sense of security. That is not okay."

-Elsa, entomologist/ policymaker/ registered restricted pest controler

As portrayed by the quotes above, the field workers are being called "vector inspectors" and perform control practices for different types of vectors (e.g. rats, flies etc.); however, according to an evaluation report and interviews with experts, these field workers only received training, limited to 2 weeks, in mosquito prevention and control strategies. Thus they are not certified to do all types of work-related to vector control. The majority of the certified inspectors retired, and during the epidemics, the VCU only had three certified inspectors. Besides the VCU and the department of E\&R, the department of communication also faced issues related to its workforce. Several interviewed experts indicated that the department of communication employees do not have the education, skills, and creativity to develop a strategic communication plan to reach the majority of the community. Mentioned issues with the workforce have been discussed with the policy department, director of the health sector, and the VCU. The data of this study revealed that this issue is known. However, limited actions have been performed in the last ten years to improve the workforce of the VCU. 
Both participants of the FGDs and interviews have questioned the manner of recruiting the workforce of the health system. Some experts have stated that some health professionals have been recruited based on bureaucracy and not based on professionalism and education. Mentioned manner of recruiting cause things such as a workforce with a lack of education, management skills, and capacity to deal with SIDS challenges.

\section{Medical products and technologies}

The treatment of dengue, chikungunya, and Zika relies on supportive treatment and symptom relief since there is no antiviral treatment available. According to the interviewed GPs, the health system of Curaçao had ensured equitable access to medical products during the outbreak of CHIKV infection. Besides medical products, the health system needs to arrange or collaborate with organisations to access the required technologies, such as diagnostics tools. Since laboratories play an essential role in the diagnostic of these diseases, input and collaboration between laboratories and the health system have been discussed during FGDs and interviews with experts. Several interviewed experts questioned the collaboration between the laboratories and the health system. They stated that the agreements made between GMN and laboratories, especially Analytisch Diagnostisch Centrum (ADC) laboratory, which is the public health laboratory, are not documented. This causes no reporting or delay in reporting laboratory-confirmed cases of VBDs, no sustainable collaboration, and lack of cost-effectiveness. The following quote portrays the mentioned issues: 


\begin{abstract}
"Male 2: The performance of $A D C$ is not in concordance with the guidelines of a public health laboratory. That is not good.

Male 1: The government never defined $A D C$ 's role as "the national public health laboratory". The government just mentioned its role, but it has not been documented.

Male 1: They have a severe problem.

Female 1: Yes, they have a problem.

Male 2: Yes, there is a problem. When I started with my job in 2008, the the government gave the national laboratory 2.8 million guilders for public health issues (e.g., to pay laboratory tests).

Male 1: Annually.

Male 2: Annually? Really?

Male 1: Yes.

Male 2: But it strange, because if the government needed laboratory tests, they needed to pay for the tests again.

Male 1: Yes, we[GMN] needed to pay again.

Male 2: This happened during the dengue outbreak.

Male 1: And in the period of Zika, we [GMN] paid ADC more money." -FGD with health professionals working for the GMN
\end{abstract}

An interview with a representative of ADC was conducted to hear their side of the story. However, limited information concerning the collaboration and agreements between the health system and ADC was provided. ADC only indicated that they need to diminish information concerning VBDs when the health system asks for it (e.g., during an epidemic). In contrast, the health system expects their collaboration during the entire year for the surveillance of VBDs. The mentioned unsolved structural problems within this building block obstruct performance, the quality and efficacy of the surveillance system of cases, health promotion and vector control efforts (e.g. inspection of mosquitoes breeding sites at houses of infected cases and their surrounding).

\title{
Service delivery
}

According to observation notes, the VCU has offered the following free services to the community and organisations to prevent and control mosquitoes during the last three epidemics of VBDs: (i) inspect houses of infected locals and their neighbours for mosquito breeding sites, (ii) provide larvicide (e.g., Abate $^{\mathrm{TM}}$ ), (iii) fumigation, (iv) provide guppies (Poecilia reticulate), and (v) perform health promotion. Several experts questioned the service delivered by the VCU. They indicated that the service delivered was 
obstructed by the following factors; insufficient larvicide, educated field workers, entomological field equipment, financial support, guidance, and collaboration between governmental and non-governmental organisations. Two evaluation reports have confirmed the mentioned statement.

Furthermore, an evaluation report written by two external entomologists indicated that little scientific literature had been used to update vector control practices in the last decade. A local entomologist has confirmed this statement by giving the following example: Abate ${ }^{\mathrm{TM}}$ was previously primarily used, but it was replaced with an environmentally friendly substance, Aquabac ${ }^{\mathrm{TM}}$. In 2018, Abate ${ }^{\mathrm{TM}}$ was re-introduced by the former head of the VCU without taking related consequences (e.g., insecticide resistance) into account. The following quote portrays this issue:

"Female 1: Yes, we had all that stuff [larvicide]. I introduced a growth hormone. What is its name
again? Interviewer: Bti Bacillus something.

Female 1: Bacillus thuringiensis israelensis (Bti) $\left(\right.$ Aquabac $^{\mathrm{TM}}$ )

Interviewer: But Bti was replaced with Abate.

Female 1: That is a bad idea. In many aspects, it is a bad idea.

Interviewer: But as a toxicologist, he should know that.

Female 1: But he does not understand environmental health. Look, please consider this information and take it with you. Maybe you know this already. Abate is still helpful to combat larvae; vectors are predominantly resistant to many substances nowadays. Thus, Abate needs to be your last resource. If you are using it in the long term, you need to plan to switch the substances you are using.

Interviewer: Thus, it is like you start treating everybody in the hospital with Colistine?

Female 1: Exactly. It's a bad idea, and I told them,".

-Elsa, entomologist/ policymaker/ registered restricted pest controller

Abate $^{\text {TM }}$ and Aquabac $^{\text {TM }}$ usage within the VCU was also a concern of many experts. They stated that the fieldworkers do not know how to work with larvicide (Abate ${ }^{T M}$ ) and Aquabac ${ }^{T M}$. The fieldworkers themselves have confirmed this statement. The following quote portrays this issue:

"Male 1: The employee that hand out Abate; he works in the storeroom; he does not know how to deal with Abate and Bti. He cannot give the correct information. He got some information, and that is what he is using. Just let me asks them [field workers], how much Bti or Abate do you need to treat a small pool? They do not know.

Moderator: Thus, what you mean is that the guideline to use Abate and Bti is not clear? Moreover, you are using these products based on feelings?

Male 1: Yes.

Male 2: Yes. Just like that."

-FGD with the workforce of the VCU 
As portrayed by the quote above, the lack of knowledge and skills concerning the usage of biological and chemical substances to prevent and control VBDs obstruct the health system's performance.

Lastly, some experts stated that the vector control during house inspections has deteriorated because the fieldworker's work has not been evaluated and supervised by educated inspectors in the last decade. This causes distrust towards the VCU and their collected entomological data. Field excursions with the fieldworkers demonstrated unethical behaviour (e.g., falsified house inspection) that diminishes trust towards the VCU. On the other hand, no access to properties and inhabited houses also obstructs the fieldwork of the VCU. According to some experts and observation notes, many assigned houses are not inspected since the owners are not at home during the working hours of the VCU. Another bottleneck is the planning to perform vector control in a year. Vector control starts at one side of the island and finishes on the other side. There are no assigned teams for specified neighbourhoods. Several experts have questioned this approach since it demonstrated to be not efficient in preventing and dealing with an outbreak. They also stated that prevention, including RC and mosquito control measures, had been implemented reactively (in response to outbreaks, severe nuisance, and infected cases) and not from a proactive perspective. 
Action plan to improve the performance of the health system of Curaçao

Phase 1: Actions to improve prevention and control strategies concerning VBDs

- Assign three health professionals with VBDs, management, and public health experience to coordinate actions related to the prevention and control of VBDs.

- Institute a multidisciplinary team (MDT) including an entomologist, epidemiologist, communication expert, certified vector inspector, sociologists, surveillance systems specialist, laboratory representative (e.g., microbiologist), policymaker, environmental specialist, and if possible, $\mathrm{PhD}$ students that have been working in this field.

Note: The three assigned health professionals are responsible for the documentation, dissemination of information, and coordination of the teamrelated activities. They are members and representatives of the MDT.

- Evaluate, adjust and promote laws/policies regarding infectious diseases and vector control (e.g., the existent Integrated Management Strategy for Dengue Prevention and Control in Curaçao, 2012).

- Make a protocol for the usage of biological control measures (e.g., guppies, (Poecilia reticulate), Aquabac ${ }^{T M}$ ) and the usage of chemical control measures (e.g., larvicide, e.g., AbateTM), including related safety procedures.

- Evaluate and provide recommendations to improve the working procedure related to housing inspections (e.g., create teams, VCU field workers under the supervision of certified vector inspectors that are responsible for specific neighbourhoods/ geo zones).
Responsible

The management team of the GMN

Three assigned health professionals

The MDT and the policy department

The entomologist, certified vector inspector, environmental specialist, and policymaker

The MDT

\section{Actions to enhance capacity building}

- Make job descriptions for the workforce of the health system that works in the field of prevention and control of VBDs.

Note: HR recruit future health professionals based on developed job descriptions.

- Seek ways to acquire funds to organise training for the workforce in different aspects (e.g., entomology, surveillance, $R C$, geographic information system (GIS), equipment calibration, pesticide safety).

- Make use of local published data (e.g., PhD students) to make decisions and use the research skills of these PhD students to perform the necessary research, for example, in the field of social sciences and entomology.

- Perform insecticide resistance and entomological research (e.g., to determine the house index container index, breteau index, and pupal index) to guide vector control strategies.

- Seek funding to create a basic entomological laboratory to perform basic entomological research.
Human resources (HR) and the representatives of the MDT

The representatives of the MDT

The MDT

The entomologist and the VCU

The representatives of the MDT 
Phase 1: Actions to improve prevention and control strategies concerning VBDs

- Seek ways to connect both governmental organisation and NGOs that are needed for prevention and vector control, e.g., Selikor (waste management), Caribbean Research and Management of Biodiversity (CARMABI), Ministery of Traffic, Transport and Urban Planning and Ministery of Social Development, Work and Welfare, Ministry of Education, Science, Culture and Sport, and laboratories.

- Document agreements between organisations to enhance accountability and transparency.
Responsible

The representatives of the MDT, management specialist, sociologist, and policymaker

\section{Actions to reform the health system}

- Examine and determine the organisational culture of the health system.

- Make a plan to improve the management and culture style of the health system. Provide recommendation to reinforce the organisational structure of the GMN.

- Evaluate the motivation, job satisfaction, and abilities of the workforce of the health system.

Management specialist, sociologist, policymaker, and HR

HR

\section{Discussion}

This qualitative study aimed to examine the performance of the health system of Curaçao with regards to the prevention and control of VBDs in the last decennium by using the WHO health system building blocks. The following organisational bottlenecks: insufficient collaboration between governmental and NGO's, leadership skills, coordination, structure, communication within and outside the health system, qualified health workforce, and capacity-building affected the performance of the health system negatively. Other SIDS in the Caribbean (21) and the Pacific (22) also struggle with similar organisational bottlenecks. Mentioned bottlenecks have obstructed the development, approval, and implementation of laws/guidelines and interventions, such as the Integrated Vector Management (IVM) program. Similar results were found in other studies that also researched challenges in vector control in the field of malaria $(23,24)$ and dengue $(25)$.

Our findings might also highlight some aspects of the organisational culture of the health system of Curaçao. We found that the workforce works in a siloed manner and avoid being blamed for mistakes. Also, they believe they must interact with people in ways that will not threaten their employment security because bureaucracy still plays an essential role. These are characteristics of the avoidance, conventional, and approval culture styles, which are associated with the passive/defensive culture style (26). Passive/defensive cultural style experience a high number of unresolved conflicts, and the workforce often reports lower levels of job satisfaction and motivation(27). These aspects were also observed in this study. This study gave some useful insights into the culture of the health system of Curaçao; however, more research (e.g., use the Organisational Culture Inventory tool) is needed to study this complex mechanism more profoundly(26).

Lastly, we observed how building blocks influence each other. For example, issues related to leadership/governance seem to influence the dissemination of information, the collaboration within and 
outside the health system (e.g., laboratories), and the budget for prevention and control of VBDs. Issues related to the health information system influence the development of prevention and control strategies, the collaboration among the health workforce, and service delivery. Furthermore, issues related to the financing system influence the quality of the health workforce (e.g., no training opportunities are offered to enhance $R C$, surveillance, and entomological practices) and the number of resources. Thus we can conclude that improving the health system building blocks without recognising their interaction will lead to unsuccessful health system structures and management systems, which will continue to fail to address the existing health challenges (28). Currently, the health system of Curaçao faces challenges in controlling COVID-19. Guidelines, oversight, collaboration, and communication are still insufficient. Thus, the above mentioned organisational bottlenecks continue to impose barriers to the health system's performance in the current pandemic of COVID-19.

\section{Limitations}

Qualitative research is often criticised because the findings cannot be generalised and do not prove causality. However, when studying organisational processes, perceptions, and experiences of people, qualitative studies provide the opportunity to understand these mechanisms profoundly. To minimise the mentioned limitations and improve this study's quality, we combined four qualitative research methods to provide a confluence of evidence that breeds credibility. Furthermore, the sample size can be considered small for this type of research. However, this sample is believed to be fairly representative of the distribution of people in the health system's hierarchy; age, gender, experience, education, and the participant's job appear to confirm this.

\section{Conclusion}

Based on our findings, we can conclude that the performance of the health system of Curaçao was not optimal during the last epidemics of VBDs. Serval internal (e.g., lack of communication, oversight, collaboration, governmental challenges that came with the dissolution of the Netherlands Antilles [new governmental structure]) and external (e.g., the economic situation [significant national debt], and political instability) factors negatively influenced the performance of the health system in the last decade. There is a strong need for an overall policy, proper job descriptions, a trained health workforce, structural communication, and collaboration. Many efforts (e.g., political involvement, financial support, health system reforms) are needed to tackle all of the challenges presented in this paper. However, we recommend starting with the reinforcement of oversight of the IVM program and administrative structure (e.g., through policies). These two elements will provide guidance, create transparency, and set the platform to communicate and collaborate within the health system. Lastly, we recommend evaluating and reforming the organisational structure of the health system. See Table 5 for the proposed action plan to improve the six building blocks of the health system of Curaçao. Undoubtedly other SIDS can also benefit from this action plan since such an action plan covering all health system building blocks to improve health system performance concerning prevention and control of VBD for SIDS is lacking. 


\section{Declarations}

\section{Ethics approval and consent to participate}

The Medical Ethical Board of the Sint Elisabeth Hospital Curaçao approved this study (METC SEHOS; reference number:2017-003). All participants signed a written informed consent. All data were anonymised and stored in files accessible only to the principal investigators.

\section{Consent for publication}

"Not applicable."

\section{Availability of data and materials}

The data supporting this article's conclusions and recommendations are included in the article, and additional data can be found in the appendix. The raw data will not be made publicly available because participants did not consent to have their full transcript available for the public. Request to access the data can be sent to leneke van der Gun, e-mail address: b.t.f.van.der.gun01@umcg.nl and Eurydice Martina (project coordinator at Curaçao Biomedical \& Health Research Institute) e-mail address: e.martina@cbhri.com.

\section{Competing interests}

The authors declare that they have no competing interests.

\section{Funding}

Funding was provided by the Netherlands Organisation for Scientific Research (NWO) to the project entitled "Public health impact of chronic chikungunya illness and performance/utilisation of the health care system in the face of arboviral (dengue, chikungunya, Zika) epidemics in Curacao" Acronym: ARBOCARIB (NWO grant ALWCA.2016.021). The funders had no role in study design, data collection and analysis, decision to publish, or preparation of the article.

\section{Authors contributions}

Vaitiare Mulderij-Jansen: Conceptualisation, Data curation, Formal analysis, Investigation, Methodology, Resources, Software, Visualization, Writing - original draft, Writing - review \& editing. Izzy Gerstenbluth: Supervision, Writing - review \& editing. Ashley Duits: Supervision, Writing - review \& editing. Adriana Tami: Funding acquisition, Project administration, Supervision, Writing - review \& editing. Ajay Bailey: Funding acquisition, Conceptualisation, Methodology, Supervision, Supervision-formal analysis, Writing - review \& editing.

\section{Acknowledgements}


We want to thank the participants and Martha Gillen for their time invested in our study. We want to thank both the editors and reviewers for their insightful comments on the paper.

\section{References}

1. Beltrán-Silva SL, Chacón-Hernández SS, Moreno-Palacios E, Pereyra-Molina J. Clinical and differential diagnosis: Dengue, chikungunya and Zika. Rev Med Hosp Gen Méx. 2018;81(3):146-53.

2. Elsinga J, van der Veen HT, Gerstenbluth I, Burgerhof JGM, Dijkstra A, Grobusch MP, et al. Community participation in mosquito breeding site control: an interdisciplinary mixed methods study in Curacao. Parasit Vectors. 2017;10(1):434.

3. Mulderij-Jansen V, Elsinga J, Gerstenbluth I, Duits A, Tami A, Bailey A. Understanding risk communication for prevention and control of vector-borne diseases: A mixed-method study in Curacao. PLoS Negl Trop Dis. 2020;14(4):e0008136.

4. Kotsakiozi P, Gloria-Soria A, Caccone A, Evans B, Schama R, Martins AJ, et al. Tracking the return of Aedes aegypti to Brazil, the major vector of the dengue, chikungunya and Zika viruses. PLoS Negl Trop Dis. 2017;11(7):e0005653.

5. Zellweger RM, Cano J, Mangeas M, Taglioni F, Mercier A, Despinoy M, et al. Socioeconomic and environmental determinants of dengue transmission in an urban setting: An ecological study in Noumea, New Caledonia. PLoS Negl Trop Dis. 2017;11(4):e0005471.

6. Bulthuis SE, Kok MC, Raven J, Dieleman MA. Factors influencing the scale-up of public health interventions in low- and middle-income countries: a qualitative systematic literature review. Health Policy Plan. 2019.

7. WHO. Everybody business: strengthening health systems to improve health outcomes: WHO's framework for action [Internet]. Geneva;2007 [cited 2020 January 31]. Available from: https://www.who.int/healthsystems/strategy/en/.

8. WHO. Monitoring the building blocks of health systems: a handbook of indicators and their measurement strategies [Internet]. Geneva 2010 [cited 2020 January 30]. Available from: https://www.who.int/healthinfo/systems/WHO_MBHSS_2010_full_web.pdf.

9. Sacks E, Morrow M, Story WT, Shelley KD, Shanklin D, Rahimtoola M, et al. Beyond the building blocks: integrating community roles into health systems frameworks to achieve health for all. BMJ Glob Health. 2018;3(Suppl 3):e001384.

10. Mounier-Jack S, Griffiths UK, Closser S, Burchett H, Marchal B. Measuring the health systems impact of disease control programmes: a critical reflection on the WHO building blocks framework. BMC Public Health. 2014;14:278.

11. Manyazewal T. Using the World Health Organization health system building blocks through survey of healthcare professionals to determine the performance of public healthcare facilities. Arch Public Health. 2017;75:50. 
12. Obermann K, Chanturidze T, Richardson E, Tanirbergenov S, Shoranov M, Nurgozhaev A. Data for development in health: a case study and monitoring framework from Kazakhstan. BMJ Glob Health. 2016;1(1):e000003.

13. Mutale W, Bond V, Mwanamwenge MT, Mlewa S, Balabanova D, Spicer N, et al. Systems thinking in practice: the current status of the six WHO building blocks for health system strengthening in three BHOMA intervention districts of Zambia: a baseline qualitative study. BMC Health Serv Res. 2013;13:291.

14. Yu D, Souteyrand Y, Banda MA, Kaufman J, Perriens JH. Investment in HIV/AIDS programs: does it help strengthen health systems in developing countries? J Glob Health. 2008;4:8.

15. Abejirinde IO, Ingabire CM, van Vugt M, Mutesa L, van den Borne B, Busari JO. Qualitative analysis of the health system effects of a community-based malaria elimination program in Rwanda. Res Rep Trop Med. 2018;9:63-75.

16. CBS. General facts Curaçao [Internet]. 2019 [cited 2020 February 19]. Available from: https://www.cbs.cw/website/general-facts-curacao_3169/.

17. Downe-Wamboldt B. Content analysis: method, applications, and issues. Health Care Women Int. 1992;13(3):313-21.

18. Nonaka D, Jimba M, Mizoue T, Kobayashi J, Yasuoka J, Ayi I, et al. Content analysis of primary and secondary school textbooks regarding malaria control: a multi-country study. PLoS One. 2012;7(5):e36629.

19. Bastani P, Samadbeik M, Dinarvand R, Kashefian-Naeeini S, Vatankhah S. Qualitative analysis of national documents on health care services and pharmaceuticals' purchasing challenges: evidence from Iran. BMC Health Serv Res. 2018;18(1):410.

20. Bowen GA. Document analysis as a qualitative research method. 2009;9:27-40.

21. Greaves DE. Health Management/Leadership of Small Island Developing States of the Englishspeaking Caribbean:A Critical Review. J Health Manag. 2016;18(4):595-610.

22. Doyle J, Asante A, Roberts G. Human resources for health (HRH) issues and challenges in 13 Pacific Islands countries. Australia;2011.

23. Benelli G, Beier JC. Current vector control challenges in the fight against malaria. Acta Trop. 2017;174:91-6.

24. Mutero CM, Schlodder D, Kabatereine N, Kramer R. Integrated vector management for malaria control in Uganda: knowledge, perceptions and policy development. Malar J. 2012;11:21.

25. Nguyen-Tien T, Probandari A, Ahmad RA. Barriers to Engaging Communities in a Dengue Vector Control Program: An Implementation Research in an Urban Area in Hanoi City, Vietnam. Am J Trop Med Hyg. 2019;100(4):964-73.

26. Cooke RA, Szumal JL. Measuring Normative Beliefs and Shared Behavioral Expectations in Organizations: The Reliability and Validity of the Organizational Culture Inventory. Psychol Rep. 1993;72(3_suppl):1299-330. 
27. Cooke RA, Szumal JL. The Impact of Group Interaction Styles on Problem-Solving Effectiveness. J Appl Behav. 1994;30(4):415-37.

28. Senkubuge F, Modisenyane M, Bishaw T. Strengthening health systems by health sector reforms. Glob Health Action. 2014;7:23568.

\section{Figures}

Health System Building Blocks

\begin{tabular}{|l|}
\hline Leadership/governance \\
\hline \hline Health information system \\
\hline \hline Financing system \\
\hline Health workforce \\
\hline Medical products \& technologies \\
\hline \hline Service delivery \\
\hline
\end{tabular}

Overall goals/Outcomes

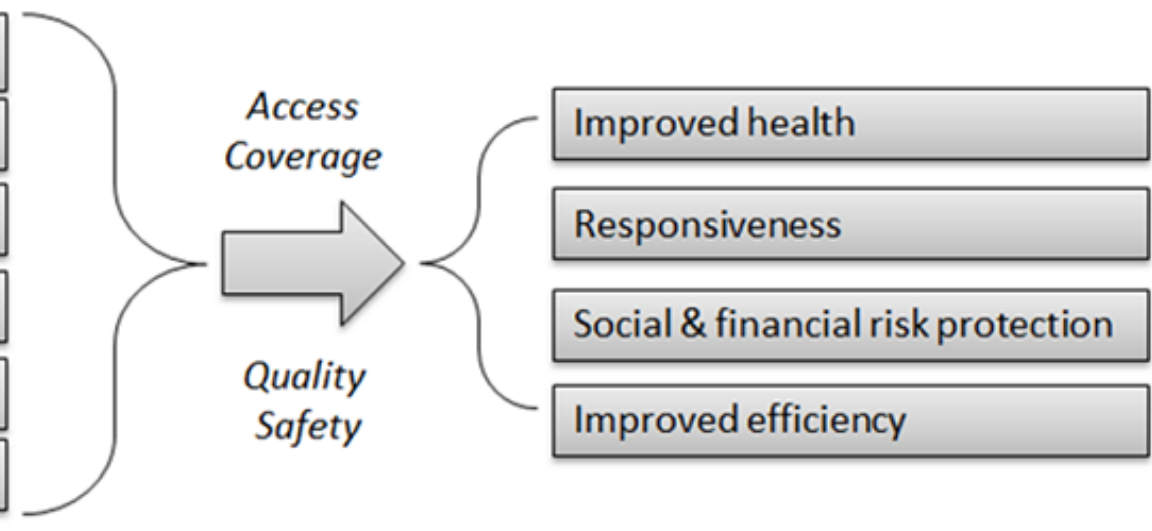

\section{Figure 1}

The WHO Health System Building Blocks Framework

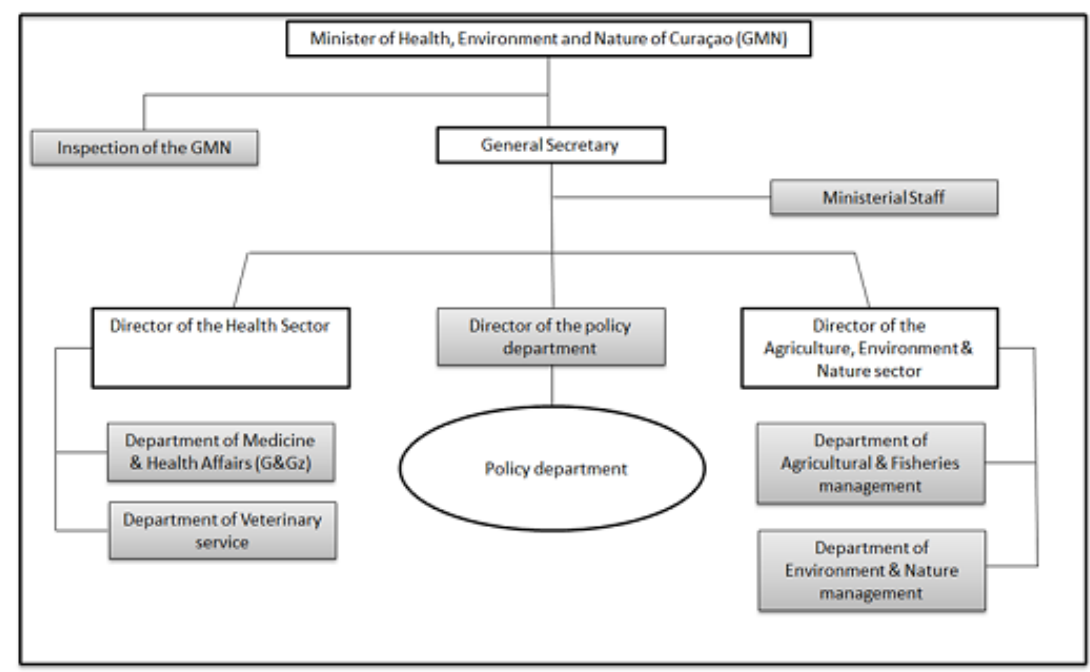

\section{Figure 2}

The organisational chart of the Ministry of Health, Environment and Nature of Curaçao. Adapted from Curaçao: Business plan, Ministery of Health, Environment and Nature (p. 10), by GMN, 2011. Adapted with permission. 


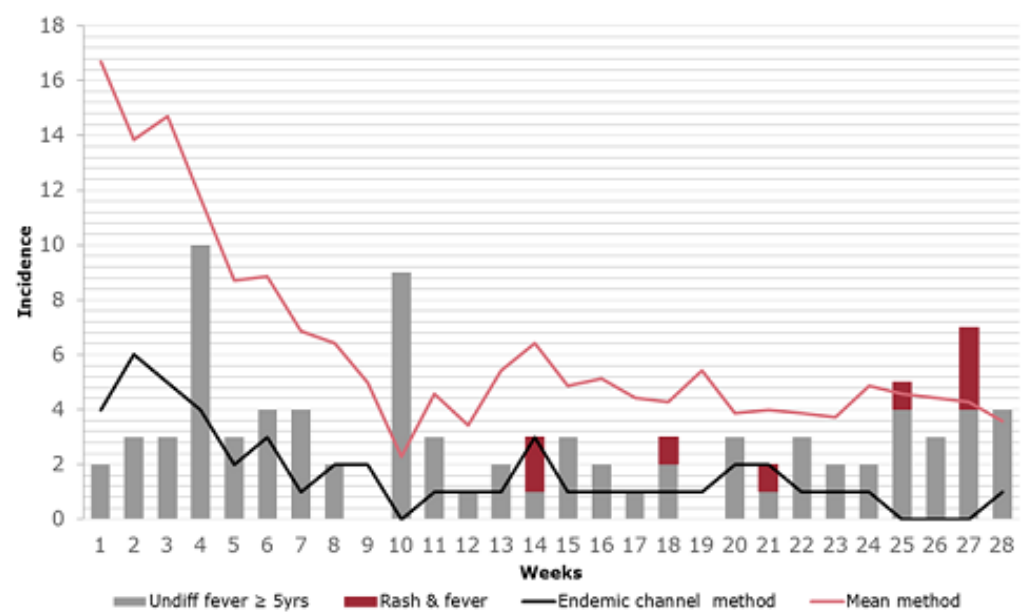

\section{Figure 3}

Comparison of two cut-off values to detect outbreaks. Reprinted from Syndromic Surveillance 2020, by the Department of Epidemiology and Research Unit Curaçao, 2020. Note: Both methods use fever and rash as a proxy for DENV, CHIKV, and ZIKV infection.

\section{Supplementary Files}

This is a list of supplementary files associated with this preprint. Click to download.

- Additionalfile1.docx

- Additionalfile2.docx

- Additionalfile3.docx

- Additionalfile4.docx

- Additionalfile5.docx

- Additionalfile6.docx

- Additionalfile7.docx 